\title{
Dinámica espacio-temporal de uso, cambio de uso y cobertura de suelo en la región centro de la Sierra Madre Oriental: implicaciones para una estrategia REDD+ (Reducción de Emisiones por la Deforestación y Degradación)
}

Spatio-temporal dynamics of use, change of use and land cover in the central region of the Sierra Madre Oriental: Implications for a REDD+ strategy (Reduction of emissions from deforestation and degradation)

\author{
Edgar C. Leija' \\ Numa P. Pavón ${ }^{2}$ \\ Arturo Sánchez-Conzález ${ }^{3}$ \\ Rodrigo Rodríguez-Laguna ${ }^{4}$ \\ Gregorio Ángeles-Pérez ${ }^{5}$
}

Recibido 30 de agosto de 2020; aceptado 7 de octubre de 2020

\section{Resumen}

En México, la deforestación de los bosques y selvas han colocado a una gran variedad de especies de flora y fauna en peligro de extinción. Este impacto,

Universidad Nacional Autónoma de México, México, correo electrónico: eleija@ciga.unam.mx.

ORCID: 0000-0003-3142-0924

Universidad Autónoma del Estado de Hidalgo, México, correo electrónico:npavon@uaeh.edu.mx.

ORCID: 0000-0003-0666-5268

Universidad Autónoma del Estado de Hidalgo, México, correo electrónico: arturosg@uaeh.edu.mx.

ORCID: 0000-0002-3190-8789

Universidad Autónoma del Estado de Hidalgo, México, correo electrónico: rlaguna@uaeh.edu.mx.

ORCID: 0000-0002-1014-8784

Colegio de Postgraduados, México, correo electrónico: gangeles@colpos.mx.

ORCID: 0000-0002-9550-2825

Nota: Este artículo se genera a partir del trabajo de la tesis doctoral de Edgar Gregorio Leija Loredo, merecedor de una mención en la Convocatoria Premio "Pedro Vicente Maldonado" a la mejor tesis de doctorado en las áreas de Cartografía, Geodesia o Información Ceográfica, edición 2020, de la Comisión de Cartografía del Instituto Panamericano de Geografía e Historia. Las figuras y cuadros que se presentan fueron previamente publicadas en dos artículos incluidos en la tesis por lo que se mencionan las respectivas citas. 
genera grandes emisiones de gases de efecto invernadero a la atmósfera. En el presente trabajo analizó la dinámica de cambio en la cobertura y uso de suelo en la región centro de la Sierra Madre Oriental, particularmente en la región Huasteca. Se interpretaron y clasificaron tres imágenes de satélite Landsat (1986, 1990 y 2000) y una imagen de satélite Spot 2015. Se calcularon las tasas de deforestación a través del método propuesto por la Organización de las Naciones Unidas para la Alimentación y la Agricultura (por sus siglas en inglés _FAO). Se elaboraron los escenarios a futuro con el Software DINAMICA EGO, para conocer las tendencias de cambio de las coberturas y usos del suelo al 2030 y 2050. Se estimó el potencial de carbono en dos fragmentos de bosque mesófilo en los municipios de Tlanchinol y San Bartolo, a través del método NDVI y con base al INFyS de la CONAFOR para la implementación de una estrategia futura de REDD+. Los resultados muestran que para la región Huasteca, las tasas de deforestación anual oscilan entre el $0.7 \%$ y $4.5 \%$ y para los fragmentos de bosque mesófilo entre el $1.3 \%$ y $1.5 \%$, mismas que son transformadas para áreas agropecuarias. La cantidad de carbono estimada para ambos fragmentos de bosque fue de 13539.84 toneladas por hectárea para el municipio de Tlanchinol y 4363.02 toneladas de carbono por hectárea para el municipio de San Bartolo. Por ello, REDD+ permitiría frenar el avance de la deforestación en la Huasteca y de los fragmentos de BMM en la región centro de la Sierra Madre Oriental. Sin embargo, es necesario involucrar estudios como el de este trabajo para la construcción de una estrategia futura orientada a un manejo integral del territorio de manera sustentable.

Palabras clave: cambio en el uso del suelo, REDD+, bosque mesófilo de montaña, DINAMICA EGO, modelos espaciales.

\section{Abstract}

In Mexico, deforestation of forests have placed a wide variety of species of flora and fauna in danger of extinction. This impact generates large emissions of greenhouse gases into the atmosphere. This work analyzed the dynamics of change in coverage and land use in the central region of the Sierra Madre Oriental, particularly in the Huasteca region. Three Landsat satellite images (1986, 1990 and 2000) and one Spot 2015 satellite image were interpreted and classified. Deforestation rates will be calculated using the method proposed by (Food and Agriculture Organization -FAO). Future scenarios were developed with the DINAMICA EGO Software, to know the trends of change in land cover and uses up to 2030 and 2050. The carbon potential is estimated in two fragments of tropical mountain cloud forest (TMCF) in the municipalities of Tlanchinol and San Bartolo through the NDVI method and based on INFYS from CONAFOR for the implementation of a future REDD+ strategy. The results indicated for the Huasteca region, the annual deforestation rates range between $0.7 \%$ and $4.5 \%$ and for the tropical mountain cloud forest 
fragments between $1.3 \%$ and $1.5 \%$, which are transformed for agricultural areas. The estimated amount of carbon for both fragments of bosque was 13 539.84 tons per hectare for the municipality of Tlanchinol and 4363.02 tons of carbon per hectare for the municipality of San Bartolo. For this reason, REDD+ would slow down the advance of deforestation in Huasteca and the fragments TMCF in the central region of the Sierra Madre Oriental. However, it is necessary to involve studies such as that of this work for the construction of a future strategy aimed at a comprehensive management of the territory in a sustainable way.

Key words: change in land use, REDD+, tropical mountain cloud forest, DINAMICA EGO, spatial models.

\section{Introducción}

El bosque tropical ha disminuido su superficie de manera dramática en los últimos cien años. En actualidad las extensiones de bosque tropicales primarias ocurren en fragmentos aislados en zonas frecuentemente inaccesibles para las actividades humanas. Mientras que la mayor parte de los fragmentos corresponden a bosque tropicales secundarias que están rodeadas de pastizales inducidos y tierras agrícolas. A nivel global, el área cubierta por bosque tropical varía, de acuerdo a las imágenes de satélite utilizadas y métodos empleados, con un promedio de 1457.3 x 106 ha (Wright, 2005). América es el continente con mayor porcentaje de bosque tropical total con 58.1. Sin embargo, en general ha tenido la mayor pérdida de bosques (FRA, 2015) y en particular para las bosque tropical tiene las tasas de deforestación más altas con un promedio de 2.56\% (Wright, 2005; Kim et al., 2015).

Los procesos de deforestación de bosques tropicales han afectado los servicios ecosistémicos, tales como, la regulación del clima, el almacenamiento de carbono y la disponibilidad de agua (Foley et al., 2005). Además, el cambio de uso de suelo es la principal causante de extinciones locales de especies (Foley et al., 2005). Estos procesos han sido impulsados por la combinación de factores sociales, económicos y políticos (Lambin et al., 2001; Bonilla-Moheno et al., 2012). La expansión de la frontera agrícola y ganadera (Lambin et al., 2001; Munsi et al., 2010; Leija y Pavón, 2017; Leija et al., 2020) es la principal causante de deforestación como producto de un aumento en la presión en la producción de recursos, los mercados, la globalización y la pérdida de capacidades y actitudes locales (Lambin et al., 2001).

La pérdida de cobertura forestal debido al cambio de uso de suelo ha contribuido significativamente en la emisión de $\mathrm{CO}_{2}$ a la atmosfera. Considerando la incertidumbre en las estimaciones se considera que entre 2000 2005 las regiones tropicales contribuyeron entre el 7 y $14 \%$ de las emisiones 
antropogénicas totales globales, y en particular en Latinoamérica se generó 54\% de las emisiones por deforestación (Harris et al., 2012). Sin embargo, esta región de acuerdo con FAO (2010), tiene la cuarta parte de los bosques del mundo (23.5\%) y mantiene en biomasa forestal $34.6 \%$ total mundial de carbono. En el marco de política climática internacional, la estrategia REDD+ implica la reducción de emisiones pero a su vez la oportunidad de generar mejores estimaciones de carbono en bosques para establecer líneas base con información desagregada que establezcan normas y procedimientos adecuados a las condiciones de cada país (Corbera et al., 2010; Corbera \& Schroeder, 2011).

México aún mantiene grandes extensiones forestales tropicales que están en riesgo por el cambio de uso del suelo. En particular el bosque mesófilo de montaña (BMM), representa un ecosistema que mantiene una alta biodiversidad y genera servicios ecosistémicos (reservorios de carbono y producción hídrica), que sin embargo están en peligro de desaparecer por su reducida extensión y el alto impacto de las actividades humanas (Hamilton, 2012). En México el BMM se distribuye en regiones donde habitan comunidades altamente marginadas y con bajo índice de calidad de vida que ejercen una fuerte presión sobre los ecosistemas. La estrategia REDD+ sería un incentivo para mejorar los ingresos económicos de los indígenas poseedores de la tierra y de esta manera reducir en parte la deforestación forestal. El avance de la REDD+ en México implica considerar áreas propicias para su establecimiento a partir de análisis de factibilidad que incluyan en principio estimaciones de cambio de uso de suelo por deforestación y las estimaciones de emisiones de carbono; aunada la biodiversidad asociada a los bosques. Gran parte de la distribución del BMM en México ocurre en la Sierra Madre Oriental (CONABIO, 2010) donde aún no se han propuesto sitios plausibles para ser considerados dentro de la estrategia nacional REDD+ (ENAREDD).

El objetivo de este trabajo fue analizar la dinámica de cambio en el uso de suelo y las coberturas vegetales en la región centro de la Sierra Madre Oriental, particularmente en la región Huasteca, conformada por los estados de San Luis Potosí, Hidalgo, Veracruz y dos municipios del Estado de Hidalgo. Se interpretaron y clasificaron tres imágenes de satélite Landsat (1986, 1990 y 2000) y una imagen de satélite Spot 2015. Se calcularon las tasas de deforestación para ambos sitios a través del método propuesto por la FAO. Posteriormente, se elaboraron los escenarios a futuro con el Software DINAMICA EGO, para conocer las tendencias de cambio de las coberturas vegetales al 2030 y 2050. Por último estimó el potencial de carbono en dos fragmentos de bosque mesófilo en los municipios de Tlanchinol y San Bartolo a través del método NDVI y con base al INFyS de la CONAFOR para conocer su viabilidad y discutir la implementación de una estrategia futura de REDD+. 


\section{Materiales y métodos}

\section{1. Área de estudio}

\subsubsection{Región Huasteca}

Es un mosaico con tres principales coberturas: la agrícola, el pastizal inducido y el bosque tropical secundario. Se ubica entre las coordenadas geográficas $20^{\circ}$ $34^{\prime}$ y $21^{\circ} 26^{\prime} \mathrm{LN}$, y los $99^{\circ} 14^{\prime}$ y $97^{\circ} 21^{\prime} \mathrm{LW}$ y tiene una extensión de $8479 \mathrm{~km}^{2} \mathrm{con}$ altitud que varía entre 200 y 1000 msnm. La precipitación para la zona oscila entre 1000 y $3000 \mathrm{~mm}$ anuales. Se encuentran suelos como litosol, vertisol, rendzina, feozem, fluvisol, Luvisol, cambisol y Regosol (INEGI, 2003).

\subsubsection{Bosque mesófilo de montaña}

Los fragmentos forestales de BMM fueron seleccionadas en la zona centro de la Sierra Madre. Uno de estas áreas está ubicada en dentro del municipio de

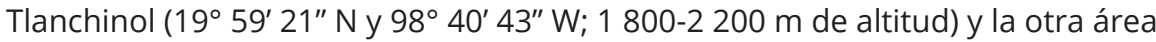
en el municipio de San Bartolo Tutotepec ( $20^{\circ} 24^{\prime} 00^{\prime \prime} \mathrm{N}$ y $98^{\circ} 12^{\prime} 00^{\prime \prime} \mathrm{W} ; 2000$ y $2600 \mathrm{~m}$ de altitud), ambos en el estado de Hidalgo, México. La superficie total de ambos polígonos fue de 22560 ha. En ambos sitios habitan población indígena con alta marginación (Ramírez-García, 2009; CONAPO, 2010) (Figura 1).

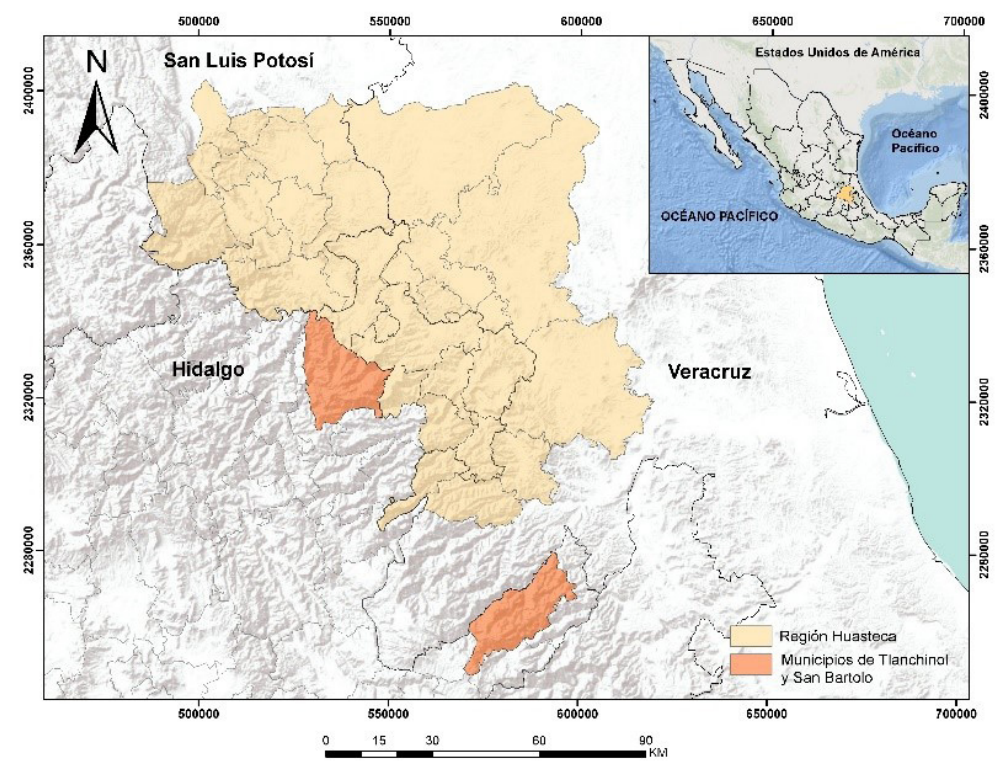

Figura 1. Área de estudio de la región Huasteca y fragmentos de bosque mesófilo en los municipios de Tlanchinol y San Bartolo Tutotepec.

Fuente: elaboración propia. 


\subsection{Fuentes de datos y análisis espacial}

Con base en la carta digital de vegetación y uso del suelo Serie V, escala 1:250 000 (INEGI, 2013) se elaboró el mapa de vegetación y usos del suelo de los polígonos. Se sobrepuso la carta digital a la imagen de satélite multiespectral Spot (2015), en la combinación de bandas RGB 432. Lo anterior permitió resaltar el vigor de la vegetación debido a que se compone de las bandas infrarrojas que contrasta los fragmentos de bosques montanos. La construcción cartográfica se realizó usando ArcGis 10.1 .

Usando los mapas se verificó la coincidencia de los polígonos de cada una de las clases presentes en la carta digital y su correspondiente tonalidad, forma y tamaño mostrado en las imágenes de satélite. Donde no hubo coincidencia entre las imágenes y la clasificación de la carta de INEGI (2013), fueron modificados o reclasificados según correspondiera. Para establecer con precisión los tipos vegetación y los usos de la tierra asociados, se realizaron verificaciones de campo mediante georreferenciación usando GPS.

Para obtener los mapas de vegetación y uso del suelo para los años 2015, 2000, 1990 y 1986 se utilizó el método propuesto por Mas (2005), el cual disminuye los errores derivados de los falsos cambios en la clasificación de los mapas. El método consistió en sobreponer la cobertura vegetal y usos del suelo de la fecha más actual (2015), sobre imágenes satelitales más antiguas (en este caso Landsat 1986, 1990 y 2000 con resolución de 30 m); con base en un análisis visual, se procedió a modificar las coberturas.

Para disminuir los errores y el nivel de incertidumbre en los mapas generados de los cambios en la cobertura vegetal en la región Huasteca y del bosque mesófilo y uso del suelo en ambos fragmentos, se llevó a cabo la evaluación de la fiabilidad temática. La cual consistió, en la evaluación del mapa de 2015, debido a que fue el mapa base para generar los de 2000, 1990 y 1986, por lo cual, la calidad de estos últimos dependería del primero. De acuerdo con lo sugerido por Olfsson et al. (2014), se determinó el tamaño de la muestra con base en una aproximación normal con base en un mapa de fiabilidad global de $90 \%$.

Se seleccionaron 600 puntos de muestreo para la región Huasteca y 40 sitios de verificación los fragmentos de BMM, con base en un muestreo de aleatorio estratificado. Este método, permitió escoger el número de sitios para cada categoría. Para corregir los sesgos de representación entre categorías se aplicó el método propuesto por Card (1982) y Olfsson et al. (2014). El cual, consiste en evaluar el valor de varios índices de fiabilidad. Así como su certidumbre (intervalo de confianza). Los índices calculados fueron: 1) la fiabilidad global (proporción del mapa correctamente clasificada), 2) la fiabilidad del usuario (relacionada con los errores de comisión de la categoría) y 3) la fiabilidad del productor (relacionada con los errores de omisión de la categoría). Asimismo, se llevó acabo la interpretación de los mapas comparando la información del mapa con el de referencia, considerado confiable, a partir de verificación de campo y 
de las imágenes de satélite de alta resolución (Mas et al. 2003). Este método permite a los usuarios del mapa valorar su ajuste con la realidad para la toma de decisiones con base en su información cartográfica (Stehman \& Czaplewski, 1998; Mas et al., 2003; Franco et al., 2006a).

Las áreas deforestadas y aquellas que cambiaron a otros usos del suelo fueron identificadas y cuantificadas por medio de sobreposición cartográfica para 2015, 2000, 1990 y 1986. La tasa de deforestación y el porcentaje de cambios para cada periodo se obtuvo mediante la fórmula empleada por la FAO (1996).

$$
C=\left[\left\{T_{2} / T_{1}\right\} 1 / n-1\right]^{*} 100
$$

Donde,

$\mathrm{C}=$ tasa de cambio

T1= es el año de inicio,

$\mathrm{T} 2=$ el año actual $o$ más reciente

n= Número de años entre T1 y T2.

Finalmente, se elaboraron los mapas de las áreas con cambios en los usos de la tierra, y se cuantificó su superficie y calcularon las tasas de cambio.

\subsection{Modelización y simulación espacial con DINAMICA ECO}

La modelización de los escenarios futuros en el uso del suelo y la transformación de la cobertura vegetal se realizó considerando las tendencias, los fenómenos espaciales y temporales con los procesos de cambio (Soares-Filho et al., 2002). Para esto se utilizó el programa DINAMICA EGO que se basa en algoritmos de autómatas celulares y los pesos de evidencia de distintas variables biofísicas y socioeconómicas identificadas como causas directos (Soares-Filho et al., 2002, 2004, 2006; Sahagún et al., 2011; Mas and Flamenco, 2011; Leija-Loredo et al., 2016, 2017). Se usaron las siguientes variables explicativas para la región Huasteca y los fragmentos de BMM: a) marginación, b) densidad de población c) vías de comunicación, d) altitud, e) pendientes, f) tipo de suelo, g) hidrología y h) cobertura y uso del suelo del mapa de 1986 y 2000. La información de las variables se obtuvo del gobierno mexicano (CONAPO, 2010; INEGI, 2005), además se incluyó las vías de comunicaciones que sirvieron para generar mapas de distancias entre terracerías y pavimentadas mediante la aplicación de un buffer de influencia (Pijaowski et al., 2002). Se incluyeron variables ambientales tales como la altitud (modelo digital de elevación), pendientes, tipo de suelo e hidrología superficial y los mapas de cobertura y uso del suelo de 1986, 1990 y 2000.

\subsubsection{Estimación de $\mathrm{C}$ en fragmentos de $\mathrm{BM} M$}

Se realizó la estimación gruesa del carbono contenido en las masas forestales usando la relación entre el NDVI y el contenido de carbono para los fragmentos 
de BMM. Previamente se estimó el carbono, a partir de mediciones dasométricas en 40 sitios con TMCF ubicados en la sierra madre. Además, para cada uno de los 40 sitios de muestreo y los fragmentos estudiando se registró el NDVI, usando dos imágenes de satélite SPOT 2015 del mes de octubre. EI NDVI se calculó mediante la siguiente expresión (Chuvieco, 1998).

$$
N D V I=\frac{(I R C-R)}{(I R C+R)}
$$

Donde, IRC es la reflectividad en la banda del infrarrojo cercano y $\mathrm{R}$ es la reflectividad en la banda del rojo. El intervalo de los valores espectrales es entre 0 y 1; debido a la reflectividad de la banda del infrarrojo cercano como la banda del rojo. Por consecuencia de estos rangos de valores, el NDVI varía su valor entre -1 y 1 (Chuvieco, 1998).

Se realizó un ajuste de regresión entre NDVI como variable explicativa y el contenido de carbono como la variable dependiente (Figura 2). La ecuación de mejor ajuste $(r 2=0.3345, P<0.05)$ fue:

$$
\text { Carbono }=441.61(N D V I) 2-176.1(N D V I)+25.9
$$

En los polígonos estudiados de Tlanchinol y San Bartolo se registraron valores de NDVI entre -0.35 y 0.54 , que fueron clasificados en 20 intervalos de clase. Se calculó el área de cada clase dentro de los fragmentos. Se realizó una estimación de carbono utilizando el valor promedio de NDVI de cada intervalo. Posteriormente el valor obtenido fue multiplicado por el área que ocupaba cada clase dentro de los fragmentos de bosque. Los análisis fueron hechos usando ArcGis 10.1

\section{Resultados}

\subsection{Región Huasteca}

Durante el periodo 1990-2015 se mantuvo el proceso de cambio de uso de suelo en la región de la Huasteca, generando un incremento del área para actividades agrícolas y ganaderas. Por lo que el bosque tropical ha sido severamente transformado. En 25 años se perdieron 87173 ha de BT 4709 ha de bosque mesófilo de montaña y 288 ha de bosque de encino. En el año 1990, la región Huasteca registró una superficie de 394460 ha de coberturas naturales (374 180 ha de bosque tropical, 17031 ha de bosque mesófilo, 2943 ha de bosque de pino-encino y 305 ha de bosque de encino), que se redujo a 301984 ha (92 476 ha menos), 25 años después. En términos proporcionales, el bosque de encino tuvo el detrimento más drástico al perder más de su $60 \%$ de su superficie, seguido del el bosque mesófilo de montaña con 30\% y el BT con $25 \%$ de su superficie al pasar de 374180 a 286006 ha en el mismo periodo (Figura 2). 

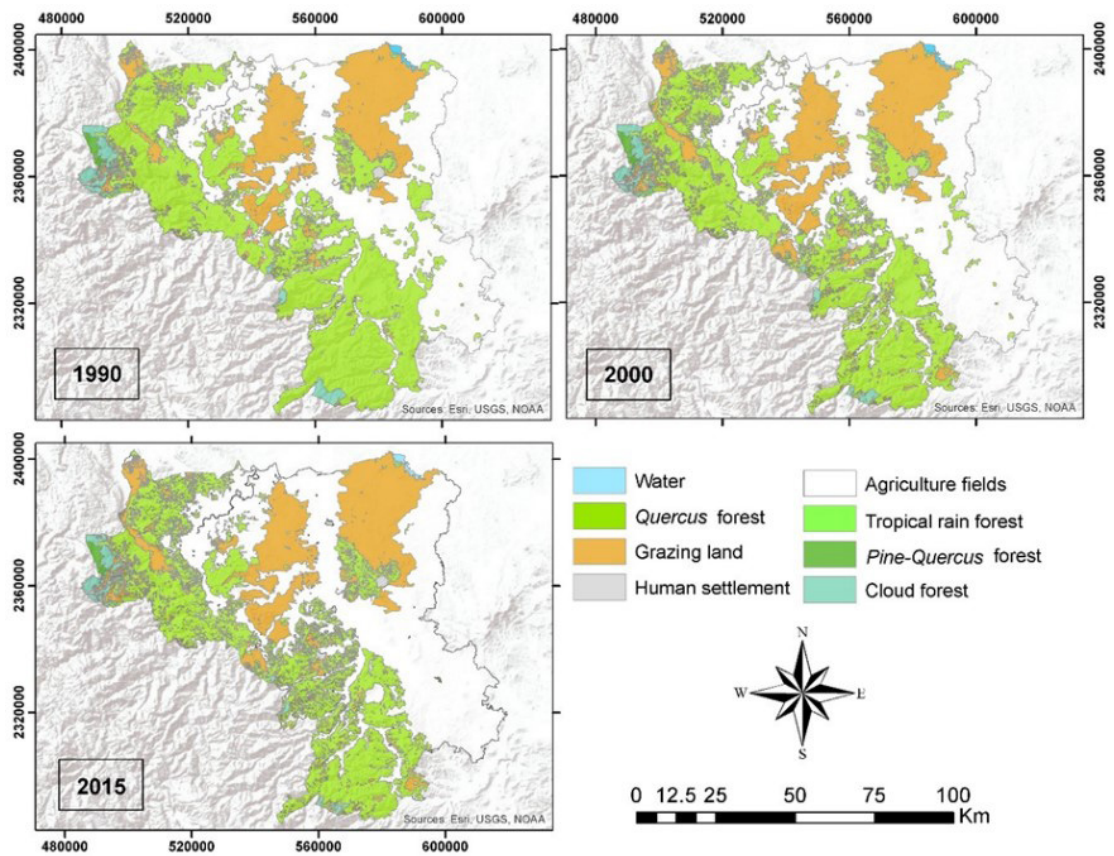

Figura 2. Vegetación y uso actual de la tierra en el área de estudio en la región de la Huasteca. Fuente: Leija y Pavón, 2017.

Las tasas de deforestación calculadas para las coberturas de vegetación natural, en el periodo 1990-2015, fueron de 1.1\% para el bosque tropical, 1.2\% para el bosque mesófilo, 0.7\% para el bosque de pino-encino, $4.5 \%$ para el bosque de encino. Se observa una importante disminución de las tasas de deforestación en el periodo 2000-2015 con respecto a la década anterior. El proceso de cambio de uso de suelo en este estudio ocurrió en las zonas de mayor altitud, en laderas y pie de monte de la Sierra Madre Oriental, dada que las zonas de menor altitud fueron fuertemente transformadas en periodos previos y actualmente tienen un uso de suelo principalmente agrícola (Figura 2). Los pastizales mostraron incrementos en su superficie al pasar de 155563 ha en 1990 a 196763 ha en 2015. Por su parte las áreas agrícolas se incrementaron en 51311 ha, en 25 años (Tabla 1).

Se obtuvieron 290 funciones de pesos de evidencia con influencia sobre los procesos de cambio de uso de suelo, de acuerdo a las ocho variables explicativas (socio-económicas y ambientales) que se utilizaron en el modelo prospectivo. Las varibles que tuvieron mayor peso en la transformación de las coberturas naturales fueron: marginación, pendiente, densidad de población, distancia a ríos y la distancia a carreteras. 
Tabla 1. Cambios en la cobertura vegetal y el uso de la tierra y las tasas de deforestación en la región de Huasteca

\begin{tabular}{|c|c|c|c|c|c|c|c|}
\hline \multirow{2}{*}{$\begin{array}{c}\text { Cobertura } \\
\text { vegetal }\end{array}$} & \multicolumn{3}{|c|}{ Área (ha) } & \multirow[t]{2}{*}{$\begin{array}{c}\text { Total } \\
\text { área (ha) }\end{array}$} & \multicolumn{3}{|c|}{$\begin{array}{c}\text { Tasa de deforestación } \\
\text { (\%) }\end{array}$} \\
\hline & 1990 & 2000 & 2015 & & $\begin{array}{l}1990- \\
2000\end{array}$ & $\begin{array}{l}2000- \\
2015\end{array}$ & $\begin{array}{l}1990- \\
2015\end{array}$ \\
\hline Selva & 374180.7 & 322546.2 & 286006.8 & -87173.9 & 1.4 & 0.7 & 1.0 \\
\hline $\begin{array}{l}\text { Bosque } \\
\text { mesófilo }\end{array}$ & 17031.1 & 14382.4 & 12321.7 & -4709.4 & 1.6 & 0.9 & 1.2 \\
\hline $\begin{array}{l}\text { Bosque de } \\
\text { pino-encino }\end{array}$ & 2943.1 & 2743.1 & 3560.4 & 117.2 & 0.7 & 1.5 & 0.7 \\
\hline $\begin{array}{l}\text { Bosque de } \\
\text { encino }\end{array}$ & 305 & 205.3 & 95.3 & -288.2 & 3.8 & 4.4 & 4.5 \\
\hline \multicolumn{8}{|l|}{ Uso del suelo } \\
\hline Pastizal & 155563.4 & 178071.1 & 196736.0 & 39613.6 & - & - & - \\
\hline Agricultura & 296792.0 & 328847.7 & 348024.7 & 51311.0 & - & - & - \\
\hline $\begin{array}{l}\text { Asentamientos } \\
\text { humanos }\end{array}$ & 7059.4 & 7079.1 & 7130.1 & 70.7 & - & - & - \\
\hline Cuerpo de agua & 2416 & 2416 & 2416 & 0 & - & - & - \\
\hline Total & 856291.2 & 856291.2 & 856291.2 & & - & - & - \\
\hline
\end{tabular}

Fuente: Leija y Pavón, 2017.

El proceso de evaluación de la confiabilidad temática muestra que los mapas de uso del suelo y cobertura vegetal del año 2015 en la región Huasteca tuvieron una confiabilidad global de $73 \%$. Este valor permite tener un alto grado de confianza en la interpretación de los mapas de cambio de uso de suelo. Además, fueron validados satisfactoriamente a través del método de muestreo aleatorio estratificado y mediante puntos de muestreo en el trabajo de campo.

Las tendencias de los cambios en las coberturas vegetales y uso de la tierra, indican que para 2050, en la región Huasteca se perderían 155856 ha de bosque tropical, 7208 ha de bosque mesófilo y 295 ha de bosque de encino. Se prevé que los mayores cambios de las coberturas naturales a otros tipos de uso sean en la franja montañosa de la Sierra Madre Oriental, principalmente en los municipios de Tamazunchale, Xilitla, Matlapa, San Felipe Orizatlán, Huejutla y Huautla. De acuerdo a las estimaciones el bosque de encino ubicado en el municipio de San Felipe Orizatlán y el bosque mesófilo ubicado en el municipio de Yahualica habrán desaparecido en los siguientes 35 años. En términos absolutos el bosque tropical será el ecosistema que pierda la mayor superficie. 


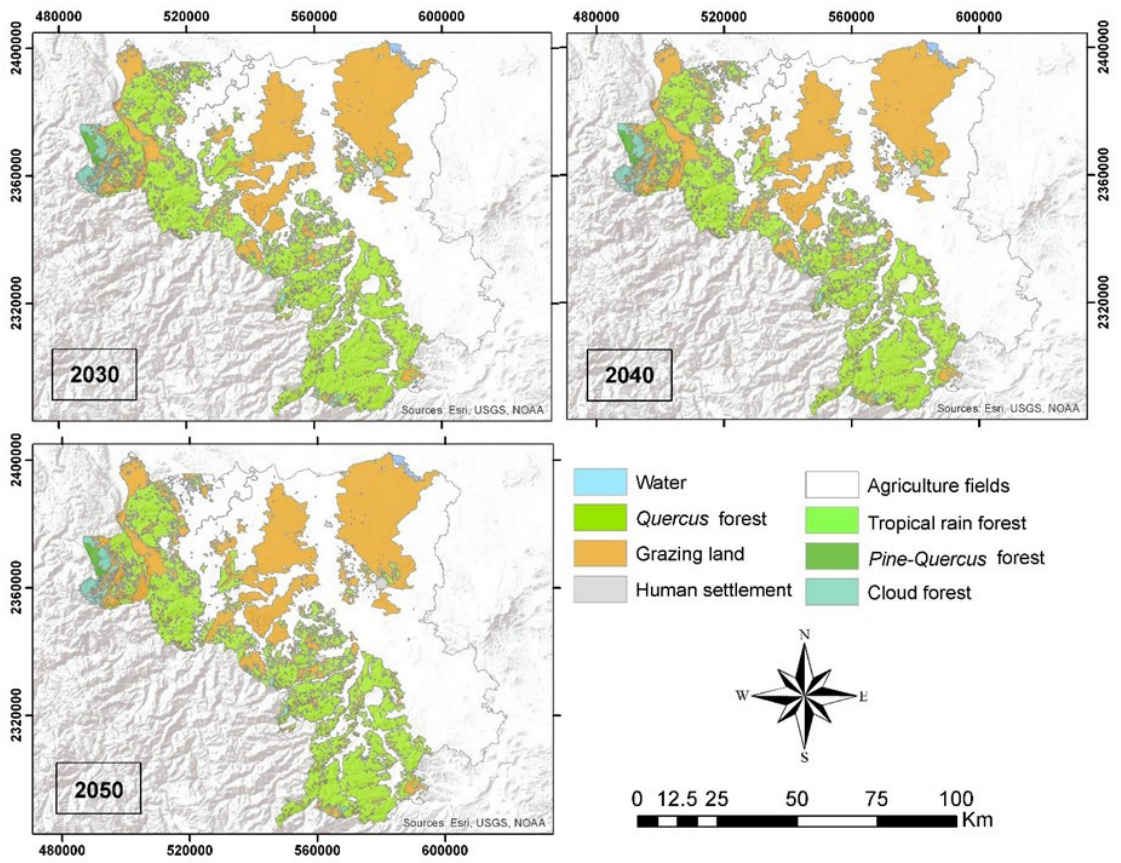

Figura 3. Los mapas muestran las proyecciones del modelo DINAMICA EGO de vegetación y uso potencial de la tierra en el área de estudio en la región de Huasteca. Fuente: Leija y Pavón, 2017.

Tabla 2. Proyecciones de escenarios futuros más cercanos de cambios en la cubierta vegetal y el uso de la tierra en la Huasteca, utilizando modelos DINAMICA EGO

\begin{tabular}{lccr}
\hline \multirow{2}{*}{ Cobertura vegetal } & \multicolumn{3}{c}{ Área (ha) } \\
\cline { 2 - 4 } & 2030 & 2040 & \multicolumn{1}{c}{2050} \\
\hline Selva & 258086.3 & 237074.1 & 218814.2 \\
\hline Bosque mesófilo & 11177.1 & 10398.7 & 9823.5 \\
\hline Bosque pino-encino & 2945.2 & 2948.9 & 2948.5 \\
\hline Bosque de encino & 13 & 9 & 9 \\
\hline Uso del suelo & 202262.4 & 210972.1 & 218814.3 \\
\hline Pastizal & 371171.3 & 384209.1 & 395623.1 \\
\hline Agricultura & 7179.6 & 7192.9 & 7264.2 \\
\hline Asentamientos humanos & 2403.3 & 2403.3 & 2403.3 \\
\hline Cuerpo de agua & & &
\end{tabular}

Fuente: Leija y Pavón, 2017. 
Por su parte los asentamientos humanos incrementarían en 205 ha para el año 2050 (Figura 3, Tabla 2).

Las actividades agropecuarias, fueron determinantes en la dinámica del cambio de uso de suelo en la región Huasteca. Para 2050 la superficie de pastizal se incrementaría a 63251 ha, mientras que la agricultura sería la actividad que ganaría mayor terreno al sumar 98831 ha. El incremento de la superficie agrícola se prevé sea acosta de la del bosque tropical (Figura 3).

\subsection{Bosque mesófilo de montaña}

En 1986, el área ocupada por bosques en los dos sitios era de 11935 ha, pero la cubierta forestal se había reducido significativamente a 7248 ha en 2015 como resultado de la conversión del uso de la tierra en pastoreo de ganado (Tabla 2). En el sitio de Tlanchinol, se deforestaron 3608 ha en 29 años, lo que representa una pérdida del 47.2\%. En el sitio de San Bartolo Tutotepec, el área boscosa era de 4291 ha en 1986. En 29 años, había disminuido a 2694 ha, una pérdida de cobertura forestal del 36.4\% (Figura 4 y Tabla 3).
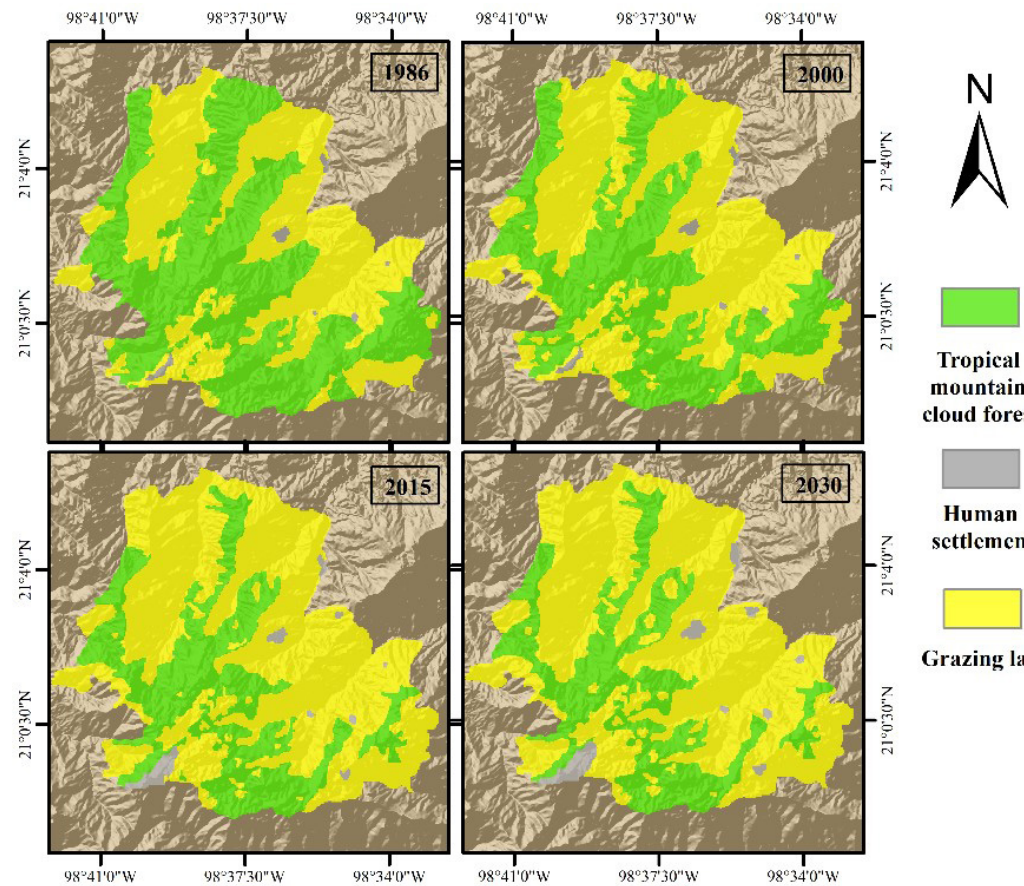

mountain cloud forest

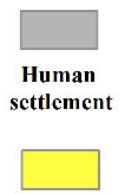

Grazing land

Figura 4. Pérdida de cobertura forestal y cambio en el uso del suelo en el polígono ubicado en el municipio de San Bartolo Tutotepec, Hidalgo, en 1986, 2000, 2015 y proyección hasta 2030 (utilizando el software Dinamica EGO). Fuente: Leija et al., 2018. 
Tabla 3. Cambios en la cubierta vegetal, tasas de deforestación y estimación del carbono total en fragmentos de bosque mesófilo de montaña

\begin{tabular}{|c|c|c|c|c|c|c|c|c|c|}
\hline \multirow{2}{*}{ Municipio } & \multirow{2}{*}{$\begin{array}{c}\text { Cobertura } \\
\text { vegetal/uso } \\
\text { del suelo }\end{array}$} & \multicolumn{4}{|c|}{ Área (ha) } & \multicolumn{3}{|c|}{$\begin{array}{c}\text { Tasa de } \\
\text { deforestación (\%) }\end{array}$} & \multirow{2}{*}{$\begin{array}{c}\begin{array}{c}\text { Total } \\
\text { Carbón } \\
\text { (ton) }\end{array} \\
2015\end{array}$} \\
\hline & & 1986 & 2000 & 2015 & 2030 & $\begin{array}{l}1986- \\
2000\end{array}$ & $\begin{array}{r}2000- \\
2015 \\
\end{array}$ & $\begin{array}{l}1986- \\
2015\end{array}$ & \\
\hline \multirow{4}{*}{ Tlanchinol } & $\begin{array}{l}\text { Bosque } \\
\text { mesófilo de } \\
\text { montaña }\end{array}$ & 7644 & 6056 & 4554 & 4036 & -1.6 & -1.7 & -1.5 & 13539.84 \\
\hline & Agricultura & 6762 & 8341 & 9711 & 10130 & ND & ND & ND & - \\
\hline & $\begin{array}{l}\text { Asentamientos } \\
\text { humanos }\end{array}$ & 102 & 111 & 243 & 342 & ND & ND & ND & - \\
\hline & Total & 14508 & 14508 & 14508 & 14508 & & & & \\
\hline \multirow{4}{*}{$\begin{array}{l}\text { San } \\
\text { Bartolo } \\
\text { Tutotepec }\end{array}$} & $\begin{array}{l}\text { Bosque } \\
\text { mesófilo de } \\
\text { montaña }\end{array}$ & 4291 & 3709 & 2694 & 2194 & -1.0 & -1.8 & -1.3 & 4363.02 \\
\hline & Agricultura & 3702 & 4237 & 5074 & 5462 & ND & ND & ND & - \\
\hline & $\begin{array}{l}\text { Asentamientos } \\
\text { humanos }\end{array}$ & 59 & 106 & 284 & 396 & ND & ND & ND & - \\
\hline & Total & 8052 & 8052 & 8052 & 8052 & & & & \\
\hline
\end{tabular}

Fuente: Leija et al., 2018.

Las tasas de deforestación anual para el período 1986-2015 fueron de -1.5\% para Tlanchinol y $-1.3 \%$ para San Bartolo (Tabla 3). Durante este período, el cambio en la cobertura de la tierra implicó la conversión del bosque en pasto para el ganado. El pasto en Tlanchinol aumentó de 6762 ha a 9711 ha y en San Bartolo Tutotepec de 3702 ha a 5074 ha. El área dedicada al asentamiento humano también aumentó en ambos fragmentos. En Tlanchinol, el área poblada aumentó de 102 ha a 243 ha y en San Bartolo de 59 ha a 284 ha (Figura 5).

El peso de la evidencia para las variables explicativas mostró que no todas ellas tuvieron una influencia significativa en el proceso de cambio. Se identificaron variables altamente correlacionadas, que tenían valores superiores a 0.45 basados en el índice de Cramer. La marginación y la elevación fueron los impulsores indirectos más importantes en los modelos de simulación de deforestación (Tabla 4). 


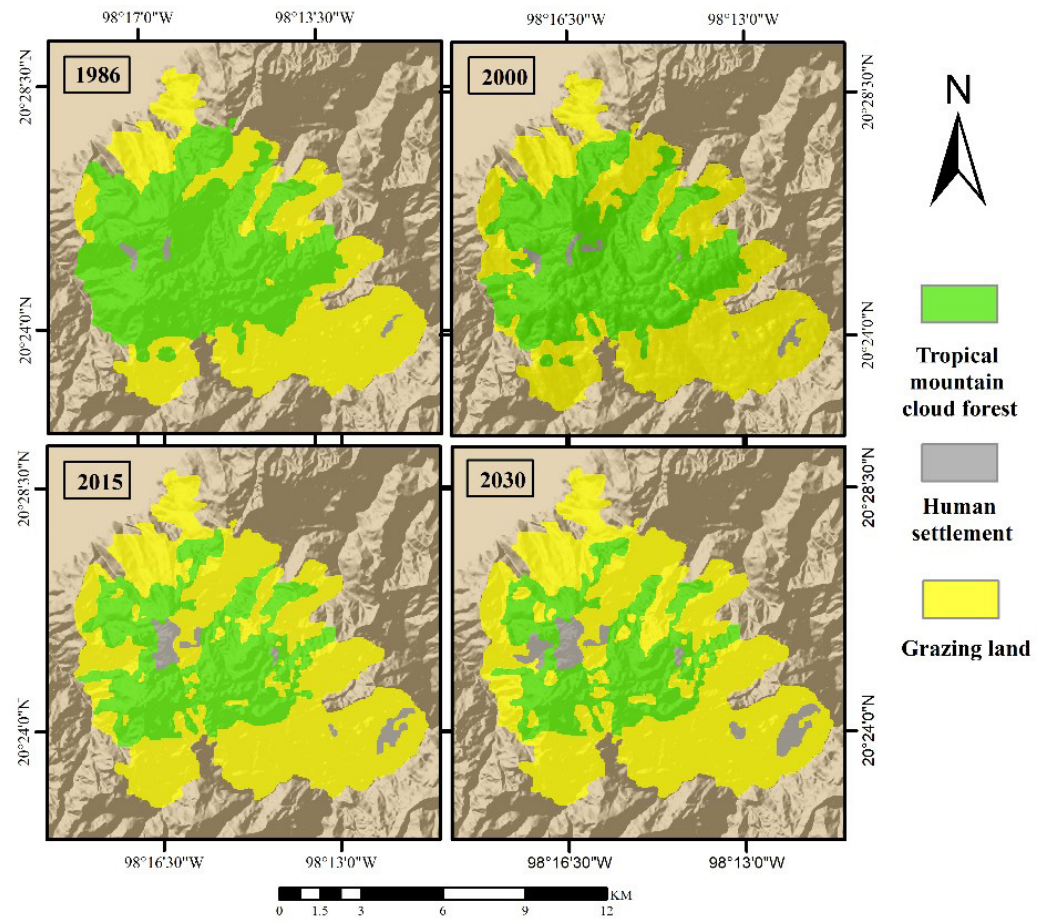

Figura 5. Pérdida de la cubierta forestal y cambio en el uso del suelo en el polígono ubicado en el municipio de Tlanchinol, Hidalgo, en 1986, 2000, 2015 y proyección para 2030 (utilizando el software Dinamica EGO). Fuente: Leija et al., 2018.

Tabla 4. Valores de peso evidencias de los impulsores indirectos de la deforestación obtenidos en los escenarios futuros de simulación del uso de la tierra y de la cubierta forestal utilizando el programa Dinamica EGO

\begin{tabular}{ll}
\hline \multicolumn{1}{c}{ Variable } & Valor \\
\hline Variable socioeconómicas & \\
\hline Marginación & 0.86 \\
\hline Densidad de población & 0.78 \\
\hline Distancia a caminos (m) & 0.83 \\
\hline Variable biophysical & \\
\hline Elevación $(m)$ & 0.65 \\
\hline Pendientes (grados) & 0.52 \\
\hline Tipo de suelos & 0.45 \\
\hline Distancia a ríos $(m)$ & 0.36 \\
\hline
\end{tabular}

Fuente: Leija et al., 2018. 
El modelo DINAMICA EGO estimó que para 2030 en ambos sitios, 3608 ha de bosques se convertirán en pastos y los asentamientos humanos aumentarán en 240 ha. En San Bartolo se perderán 2097 ha de bosque (Figuras 5 y 6), 1760 ha se transformarán en pastos y los asentamientos humanos cubrirán 337 ha (Tabla 2). En términos relativos, los fragmentos de bosque de San Bartolo Tutotepec perderían la mayor parte del área. En esta región, es notable que las áreas deforestadas, inicialmente convertidas en "milpas" (pequeños campos de cultivo, generalmente de maíz con otras plantas asociadas) bajo el método de tala y quema, eventualmente se convierten en pastizales. Esto agrava la presión sobre las áreas forestales adyacentes, al requerir más área de tierra en menos tiempo.

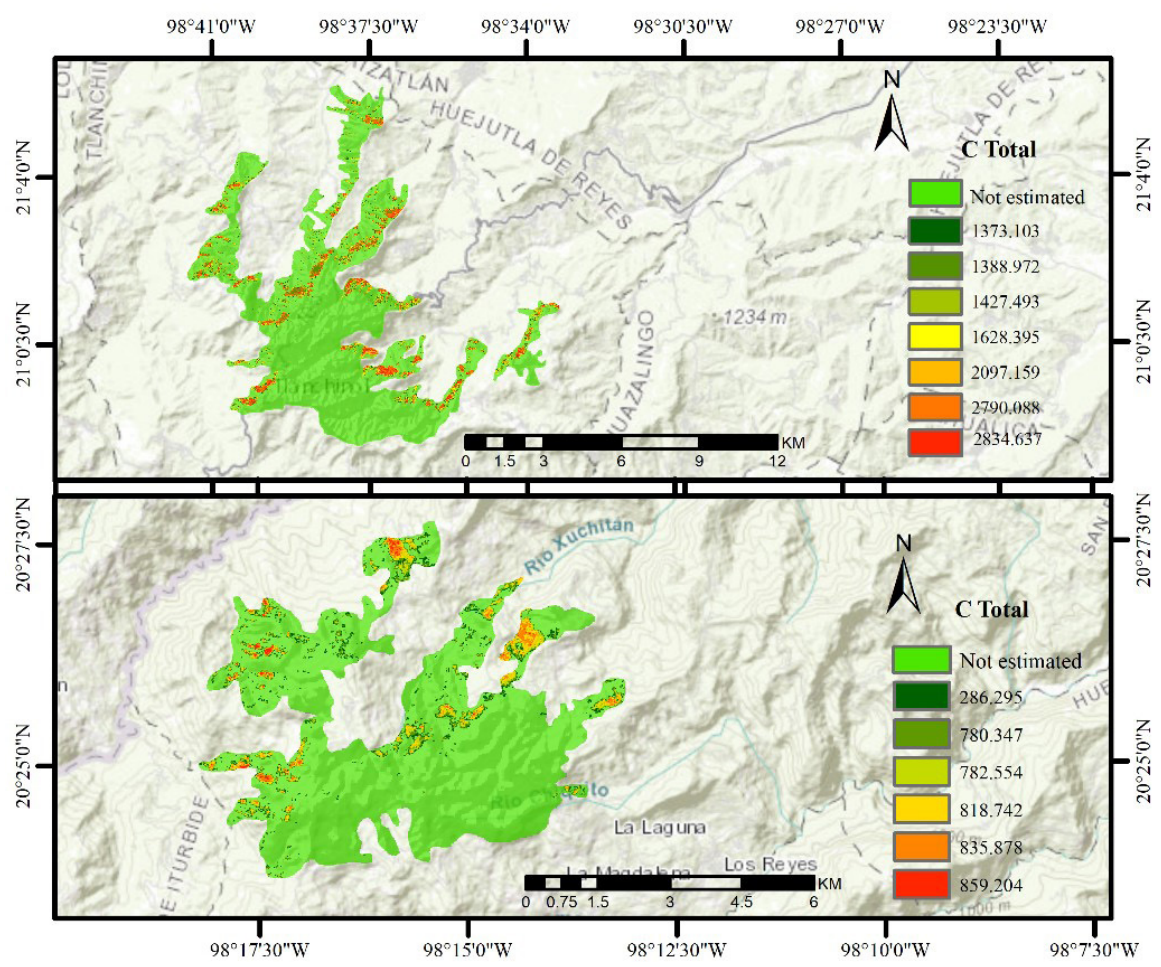

Figura 6. Carbono almacenado en el bosque nublado de montaña tropical en la zona central de la Sierra Madre Oriental, media estimada (Mg C ha-1) utilizando la teledetección. (A) polígono ubicado en el municipio de Tlanchinol, Hidalgo; Se estimó el carbono para el $18.2 \%$ de la superficie forestal del polígono, y (B) polígono ubicado en el municipio de San Bartolo Tutotepec, Hidalgo; Se estimó el carbono para el $12.8 \%$ del área del polígono.

Fuente: Leija et al., 2018. 
Solo el $18.2 \%$ del área del BMM en el sitio de Tlanchinol y el $12.8 \%$ en el sitio de San Bartolo Tutotepec tenían valores de NDVI en el rango del modelo de regresión. El resto del área en las imágenes de satélite estaba sombreada debido al terreno empinado, lo que resulta en valores bajos de NDVI. Por lo tanto, solo fue posible estimar el stock de carbono como $13539.84 \mathrm{MgC}$ (16.35 MgC ha-1) para el TMCF en Tlanchinol y 4363 MgC (12.7 MgC ha-1) para el sitio de San Bartolo (Figura 6).

\section{Discusión}

\subsection{Región Huasteca}

El bosque tropical es un ecosistema en peligro de desaparecer debido a la expansión de las actividades agropecuarias. La Huasteca representa una región tropical donde el proceso de transformación del bosque tropical ha ocurrido desde el establecimiento indígena (huastecos o tenek) prehispánico hasta la fecha. Los remanentes de bosque Tropical se han conservado en las zonas de mayor altitud y de difícil acceso, donde el proceso de transformación de uso de suelo ha sido lento pero continuo. El impacto de la colonización por los españoles provoco la creación de extensas áreas agrícolas y ganaderas en zonas planas y bajas, por ser actividades económicas rentables (Toledo, 1990; Guevara, 2001). La ganadería extensiva en México fue un modo de producción animal que homogeneizo los paisajes, convirtiéndolos en áreas principalmente de pastizales. Se sustituyó, en su mayoría, la actividad agrícola por la actividad pecuaria, convirtiéndose en una herramienta poderosa de colonización europea (Guevara, 2001). A finales del siglo XIX y principios del XX fue puesta en marcha la introducción de pastos africanos y la división de parcelas con alambres de púas, lo que ocasionó la transformación radical de los ecosistemas en la Huasteca y otras regiones tropicales (Aguilar-Robledo, 1997).

La pérdida de más de 90 mil ha de ecosistemas naturales en la Huasteca en el periodo 1990 y 2015, han generado que los paisajes en la región sean cada vez más homogéneos. Este es un proceso que en general provoca pérdida de la biodiversidad (Carpenter et al., 2009). La tala selectiva y la creación de áreas para potreros son factores que propician la fragmentación del bosque tropical, lo que altera la funcionalidad, estructura y composición de los ecosistemas (Pompa, 2008). Estudios florísticos en relictos de bosque tropical en la planicie costera del Golfo de México, documentan que solo $5 \%$ de las especies arbóreas coinciden con las especies encontradas hace cinco décadas para este tipo de vegetación (Reyes et al., 2009). Esto nos habla de la alta pérdida de biodiversidad en México a través de la deforestación. En promedio 17.9 km² de bosque tropical en México se deforestan principalmente por las actividades agropecuarias.

Las tasas de deforestación anual calculadas para la región Huasteca, oscila entre los 0.47 y $4.5 \%$, éstas se consideran altas con respecto a las reportadas 
para México (1.1\%) y otras regiones tropicales (Wright, 2005; FRA, 2015; Rosete et al., 2014; Kim et al., 2015; Leija et al., 2011). El bosque tropical, a nivel global, tiene las tasas de deforestación más altas, con un promedio de 2.56 \% (Wright, 2005; Kim et al., 2015; FRA, 2015). La deforestación de bosques tropicales en 34 países alcanzó el 62\% entre el periodo 1990-2000 (Kim et al., 2015). Para América Latina la superficie que se perdió fue de 60 millones de ha para el mismo periodo analizado. Siendo Brasil el que mayor superficie forestal neta perdió con 33\%. Asia también tuvo una acelerada pérdida neta en su superficie forestal, al pasar de 350 millones en 1990 a 318 millones de ha en 2000, perdiendo más de 30 millones de hectáreas de superficie original (Kim et al., 2015).

De acuerdo a los escenarios prospectivos, la conversión del bosque tropical hacia otros usos persistirá, por lo que seguirá reduciendo su superficie. Se estimó que para 2050 las coberturas naturales pierdan más de 160 mil ha. Siendo la agricultura la principal actividad que influirá en la apertura de nuevas tierras principalmente para la siembra de maíz. La cercanía a los ríos es el factor principal que explica la selección de sitios para la actividad agrícola. El incremento de los asentamientos humanos, también influiría en la creación de nuevos espacios, lo que implicará una mayor demanda de recursos naturales para satisfacer sus necesidades. La dinámica del proceso de deforestación implica una relación entre las variables sociales, económicas, políticas y ambientales (Pijanowski et al., 2002). Se recomienda que las proyecciones de cambio de uso de suelo se realicen a futuros cercanos. Esto debido a que las variables explicativas de los modelos pueden modificarse a corto plazo y de esta manera generar una predicción diferente (Mas et al., 2003). Por ejemplo, una política de apoyo al campo que beneficie la expansión agrícola podría acele-rar la deforestación de bosques a mediano plazo.

\subsection{Bosque mesófilo de montaña}

La deforestación es una consecuencia de la transformación del BMM en campos agrícolas y pastizales. Los fragmentos de bosque han persistido principalmente en laderas empinadas con difícil acceso, ya que el impacto humano es más pronunciado en terrenos relativamente planos (Sandel y Svenning, 2013). Los porcentajes anuales de deforestación estimados en las dos áreas de estudio fueron más altos que la tasa de deforestación de bosques montanos tropicales en todo el mundo (-1.1) (Doumenge et al., 1995). Sin embargo, los resultados fueron inferiores a los reportados en otras regiones de México. La deforestación del BMM ha sido tan alta como -1.95 en la zona occidental del cinturón transmexicano (Ruíz et al., 2016), -3.84 en la Sierra Madre Oriental (Leija et al., 2011) y -8.5 en las montañas áreas en el sureste del estado de Chiapas (Navarrete et al., 2010). Estos altos valores de deforestación muestran una tendencia preocupante para la conservación del BMM en México.

La vulnerabilidad de los fragmentos de BMM al cambio en el uso de la tierra se ilustra con la pérdida del 40\% de BMM durante 30 años debido a la deforestación. 
Esta pérdida de bosque también se traduce en la liberación a la atmósfera del carbono almacenado en BMM. Según el modelo, el BMM de San Bartolo Tutotepec disminuyo más. La tendencia a la deforestación en ambos sitios de estudio continuará hacia 2030 si no se implementan acciones de política pública para reducir la expansión de los pastos para el ganado. De los conductores indirectos incluidos en el modelo, la distancia a las carreteras aumentaría la fragmentación del bosque debido a la proximidad a los asentamientos humanos. Estos factores están relacionados con las instalaciones logísticas para la agricultura porque el terreno es con frecuencia menos empinado y accesible. Se descubrió que otro factor indirecto crucial era la marginación porque tenía un efecto positivo en la deforestación. Esto también ha ocurrido en otros países tropicales (Watson et al., 2001; Pérez-Verdin et al., 2009), donde los procesos de deforestación están convirtiendo la tierra para usos agrícolas, lo que representa ingresos para los habitantes (Ramírez-García y Castillo-Escalante, 2009). Los valores del índice de marginación fueron altos en Tlanchinol y muy altos en San Bartolo Tutotepec (CONAPO, 2010). Este factor indirecto estaría relacionado con la tasa acelerada de deforestación en ambos sitios, lo que, además de la falta de recursos económicos y capacitación técnica, ha llevado a pérdidas de fertilidad del suelo (Muñoz-Piña et al., 2003). Las áreas marginadas también carecen de bienes y servicios, como la electricidad y la estufa de gas y el carbón y la leña representan su principal combustible, lo que afecta los procesos forestales. Cabe esperar que las políticas centradas en combatir la marginación también puedan reducir las tasas de deforestación.

La deforestación debido al cambio en la cobertura del suelo implica emisiones de CO2, y también pérdidas de los servicios del ecosistema, como el mantenimiento de la biodiversidad y los procesos hidrológicos. Las condiciones ambientales del BMM permiten atraer lluvia, capacidad de infiltración, regulación del flujo de la corriente y almacenamiento de agua en el suelo (Ramírez et al., 2017). Sin embargo, la deforestación disminuye la nubosidad y la niebla en los bosques montanos que afectan los aportes de agua (Ray et al., 2006). Por otro lado, junto al bosque lluvioso de tierras bajas, el BMM es el ecosistema con la mayor biomasa vegetal y, en consecuencia, con grandes reservas de carbono para los trópicos (Spracklen y Righelato, 2014). Se han hecho pocas estimaciones de biomasa y carbono para estos ecosistemas a nivel mundial, particularmente en México. En el sureste de México, se reportaron 384.16 $\pm 40.13 \mathrm{Mg} \mathrm{C}$ ha-1 (incluidas las tiendas subterráneas) (Alvarez-Arteaga et al. 2013), y 28.8 Mg C ha-1 para la Reserva de la Biosfera El Cielo dentro de la Sierra Madre Oriental (este valor se estimó como el 50\% de la biomasa aérea reportada) (RodríguezLaguna et al., 2006).

El último valor es similar al obtenido en ambas áreas de estudio utilizando el NDVI, una medida útil para estudios de ecosistemas terrestres. El NDVI tiene en cuenta el vigor de la vegetación, que está estrechamente relacionado con el estado de los factores bióticos y abióticos y se ha utilizado como un estimador 
sustituto de la productividad primaria neta (Xu et al., 2012). Permite traducir un panorama espacial en valores netos de productividad primaria a través de la fotosíntesis y desempeña un papel esencial en el balance global de carbono (Garbulsky et al., 2008; Yu et al., 2014; Binfeng et al., 2016). Sin embargo, las reservas de carbono podrían haberse subestimado como resultado del hecho de que los valores de NDVI eran bajos o nulos porque las imágenes de satélite tenían muchas sombras debido principalmente a la orografía accidentada de la región. Por otro lado, la regresión que se ajustó al NDVI y al carbono tenía una gran incertidumbre que implica que debe usarse con precaución. También se informaron valores bajos de R2 para otros procesos de vegetación, por ejemplo, la correlación entre los flujos de CO2 y el NDVI (Burgheimer et al., 2006) Los valores de NDVI fluctúan ampliamente debido a múltiples factores, entre los cuales destaca la fenología del bosque, por lo que es importante seleccionar cuidadosamente las fechas de las imágenes de satélite para evaluar este tipo de proceso de vegetación (Meneses-Tovar, 2011). Con frecuencia, los análisis se realizan con imágenes de satélite disponibles, lo que dificulta generar mejores estimaciones.

En México, el BMM tiene una riqueza de 27000 especies de plantas vasculares, lo que representa el $10 \%$ de la flora del país, sin embargo, el $60 \%$ de las especies de árboles se encuentran en una u otra categoría de amenaza definida por la UICN (23\% vulnerable, $27 \%$ en peligro y $11 \%$ en peligro crítico) (González-Espinosa et al., 2012). Además, se han reportado 66 especies de reptiles, 36 de anfibios y 90 de escarabajos (Staphylindidae) en la zona de estudio (Ramírez-Bautista et al., 2017). La conservación forestal también tiene implicaciones adicionales para el cambio climático; por ejemplo, la adaptación basada en el ecosistema (EBA), que se define como "el uso de la biodiversidad y los servicios del ecosistema para ayudar a las personas a adaptarse a los efectos adversos del cambio climático" (Newsham et al., 2018). En el área de estudio, se concluyó que el esquema EBA podría producir resultados favorables si se mantienen los pagos por servicios ambientales u otros incentivos económicos para el desarrollo de los residentes y propietarios de tierras (Newsham et al., 2018). Por lo tanto, es esencial considerar todas las estrategias posibles, de las cuales REDD+ podría ser una de las más importantes. En este documento, mostramos que los fragmentos del bosque tienen un contenido de carbono significativo, que puede emitirse como consecuencia de la conversión del uso de la tierra al pastoreo de ganado a tasas que actualmente son de aproximadamente -1.5\%, pero que podrían reducirse si los factores socioeconómicos generan Esta pérdida de bosque se modifica. REDD+ contribuiría con recursos económicos para compensar a los propietarios de tierras que no podrían continuar llevando a cabo la deforestación. REDD+ promovería la conservación y también generaría estrategias de desarrollo para el manejo sostenible de los bosques. Las evaluaciones iniciales de los proyectos piloto de REDD+ reportan resultados positivos, como los proyectos REDD+ brasileños con una disminución en la tasa de deforestación de aproximadamente 50\% (Simonet et al., 2018). Sin embargo, 
debe tenerse en cuenta que REDD+ no es una "varita mágica" que resolvería todos los problemas socio-ecosistémicos de la región (Weatherley-Singh y Gupta, 2015), sino una estrategia esencial para generar sinergias con otras iniciativas ambientales, como pagos por servicios hidrológicos y conservación del suelo (programas del gobierno mexicano). Por otro lado, las políticas públicas efectivas contra la deforestación deben equilibrarse entre los valores ecológicos de los bosques y la importancia del sector agrícola (Nolte et al., 2017).

Finalmente, la importancia de los servicios ambientales en relación al estudio de las variables biofísicas y el uso de la tierra (Turner et al., 2016), la dinámica global, el conocimiento y la inclusión de modelos basados en agentes para comportamientos sostenibles (Alonso-Betanzos et al., 2017). Lo que permite entender el territorio como un sistema complejo en el que existen relaciones y dinámicas sociales, económicas, históricas, políticas y biofísicas en espacios permeables como el concepto del paisaje (Christensen et al., 2016; Castro-Díaz et al., 2019). En este contexto, comprender procesos complejos en un territorio, el modelado espacial surge como una forma de configurar los patrones que nutren el comportamiento de los sistemas socioecológicos (Cumming, 2011), además, de que deben incluir dimensiones temporales y espaciales como componentes de su complejidad (Perry y Enright, 2006; Castro-Díaz et al., 2019).

\section{Conclusiones}

Mediante el uso de imágenes SPOT 5 y Landsat (1986, 1990, 2000, 2015) se modelaron los escenarios de Cambio de Uso de suelo y proyección futuras usando el programa DINAMICA EGO, para la región Huasteca y ambos fragmentos de BMM en México. En esta región se encuentran los remanentes de bosque tropical más norteña de América. En el periodo 1990-2015, se perdieron 92170 hectáreas de vegetación natural debido a la expansión de la frontera agrícola y ganadera. De esta cifra la pérdida de bosques tropicales fue de $94.5 \%$. Las tasas de deforestación para esta vegetación fue alta con un promedio de $1.05 \%$. Los pastizales tuvieron un incremento en su superficie de más de 40 mil ha y el área agrícola superior a 50 mil ha. La proyección para 2050 indica que el bosque tropical tendría un área de 155856 ha lo que representa 58.4\% del área cubierta en 1990. Otros tipos de vegetación como el bosque mesófilo de montaña desaparecería del área para 2050.

Por su parte los fragmentos de BMM y de acuerdo a los resultados obtenidos, los procesos de deforestación en curso en las dos áreas de estudio con una tasa de deforestación más alta que la reportada mundialmente para TMCF. En 19862015, los pastizales aumentaron en 5068 ha, lo que representa el 42.5\% del área forestal original. Este aumento de los pastizales implica emisiones de car-bono debido a la deforestación de 12.7 a $16.35 \mathrm{MgC}$ ha-1, un valor estimado para los remanentes forestales. Los impulsores sociales indirectos de la deforestación (marginación y distancia a las carreteras) fueron los más importantes en la simulación de escenarios futuros (2030). Este resultado implica que el efecto 
de los impulsores de la deforestación opera a pequeña escala. Aunque los mecanismos de implementación aún no se han aclarado, los resultados del presente estudio son suficientes para permitirnos proponer que los bosques de Tlanchinol y San Bartolo Tutotepec dentro de la Sierra Madre Oriental en México se consideren para REDD+ como una estrategia viable para prevenir su destrucción.

\section{Agradecimientos}

Este trabajo fue posible gracias la beca otorgada al primer autor por el Consejo Nacional de Ciencia y Tecnología No. 389174 y al Posgrado en Ciencias en Biodiversidad y Conservación de la Universidad Autónoma del Estado de Hidalgo, México. Asimismo a ERMEX (Monitoreo Satelital) para el Servicio de la Información Agroalimentaria y Pesquera (SIAP) de SAGARPA, para la obtención de imágenes satelitales Spot. Los autores agradecen también a los dos revisores anónimos, por sus valiosos comentarios en este trabajo, los cuales han permitido mejorarlo.

\section{Referencias}

Aguilar-Robledo, M. (1997). Indios, ganado, tenencia de la tierra, e impacto ambiental en la Huasteca Potosina, siglos XVI y XVI. Huaxteca. El hombre y su pasado, 3, 15-25.

Alonso-Betanzos A., Sánchez-Maroño N., \& Fontenla-Romero, O. et al. (2017). Agent-based modeling of sustainable behaviors. Springer, Berlín.

Álvarez-Arteaga, G., García-Calderón, N., \& Krasilnikov, P. et al. (2013). Carbon stores in montane fog forests of the Sierra Norte de Oaxaca, Mexico. Agro-science, 2, 171-180.

Binfeng, S., Hong, Z., \& Xiaoke, W. (2016). Effects of Drought on Net Primary Productivity: Roles of Temperature, Drought Intensity, and Duration. Chinese Geographical Science, 2, 270-282. https://doi.org/10.1007/s11769-016-0804-3

Bonilla-Moheno, M., T. M. Aide, \& M. L. Clark (2012). The influence of socioeconomic, environmental, and demographic factors on municipality-scale land-use/landcover change in Mexico. Regional Environmental Change, 12, 543-557.

Burgheimer, J., Wilske, B., Maseyk, K. et al. (2006). Relationships between Normalized Difference Vegetation Index (NDVI) and carbon fluxes of biologic soil crusts assessed by ground measurements. Journal of Arid Environments, 64, 651-669. https://doi:10.1016/j.jaridenv.2005.06.025

Card, D. H. (1982). Using known map category marginal frequencies to improve estimates of thematic map accuracy. Photogrammetric Engineering \& Remote Sensing, 3, 431-439.

Carpenter, S. R., H. A. Mooney, A. John, D. Capistrano, R. S. DeFries, S. Díaz, T. Dietz, A. K. Duraiappah, A. Oteng-Yeboah, H. M. Pereira, C. Perringsk, W. V. Reidl, J. Sarukhanm, R. J. Scholesn, \& A. Whyte (2009). Science for managing ecosystem services: beyond the millennium ecosystem assessment. Procedings of the National Academy of Sciences U.S.A., 106, 1305-1312.

Castro-Díaz, R., Sione, W., Ferrero, B., Piani, V., Urich, G., \& Aceñolaza, P. (2019). Spatial Modeling of Social-ecological Systems of Hydrological Environmental Services 
in Las Conchas Creek Basin, Argentina. In Delgado L., Marín V. (Eds.) Socialecological Systems of Latin America: Complexities and Challenges. Springer, Cham. https://doi.org/10.1007/978-3-030-28452-7_11

Christensen, A. A., Brandt, J., \& Svenningsen, S. R. (2016). Landscape ecology. International encyclopedia of geography: people, the earth, environment and technology, 1-10.

Chuvieco, E. (1998). The temporal factor in remote sensing: phenomenological evolution and analysis of changes. Remote Sensing Magazine, 10, 1-9.

CONABIO (2010) El bosque mesófilo de montaña en México: amenazas y oportunidades para su conservación y manejo sostenible. Comisión Nacional para el Conocimiento y Uso de la Biodiversidad. México D.F., p. 197. Recuperado de https://bioteca.biodiversidad.gob.mx/janium/Documentos/6529.pdf

CONAPO (2010). National Population Council. Mexico: Ministry of the Interior. Recuperado de http://www.conapo.gob.mx/

Corbera, E., Estrada, M., \& Brown, K. (2010). Reducing greenhouse gas emissions from deforestation in developing countries: revisiting the assumptions. Climatic Change, 100, 355-388. https://doi.org/10.1007/s10584-009-9773-1

Corbera, E., \& Schroeder, H. (2011). Governing and implementing REDD+. Environmental Science \& Policy, 14, 89-99. https://doi.org/10.1016/j.envsci.2010.11.002

Doumenge, C., Gilmour, D., Pérez, M. R. et al. (1995). Tropical montane cloud forests: conservation status and management issues. In Hamilton, L. S., Juvik, J. O., Scatena, F. N. (eds.) (1995) Tropical montane cloud forests. Springer, New York, NY, pp. 24-37. https://doi.org/10.1007/978-1-4612-2500-3_2

FAO (1996). Forest resources assessment 1990. Survey of tropical forest cover and study of change processes, Rome.

FAO (2010). Food and Agriculture Organization. FAO Forestry Paper 159: Impact of the global forest industry on atmospheric greenhouse gases, Rome. 86 . Recuperado de http://www.fao.org/docrep/012/i1580e/i1580e00.pdf

Foley, J. A., R. DeFries, P. G. Asner, C. Barford, G. Bonan, S. R. Carpenter, F. S. Chapin et al. (2005). Global consequences of land use. Science, 309, 570-574.

FRA (2015). Evaluación de los Recursos Forestales Mundiales. Organización de las Naciones Unidas para la Alimentación y la Agricultura. Compendio de datos. Rome.

Garbulsky, M. F., Peñuelas, J., Ourcival, J. M. et al. (2008). Estimation of the efficiency of the use of radiation in Mediterranean forests from MODIS data. Use of the Photochemical Reflectance Index (PRI). Ecosystems, 3, 89-97.

González-Espinosa, M., Meave, J. A., Ramírez-Marcial, N. et al. (2012). The cloud forests of Mexico: conservation and restoration of its arboreal component. Ecosystems Magazine, 1-2, 36-52.

Guevara, S. (2001). Presentación. In L. Hernández (Ed.), Historia Ambiental de la Ganadería en México. Instituto de Ecología, A. C. Xalapa, México, 1-6.

Hamilton, L. S., Juvik, J. O., \& Scatena, F. N. (Eds.). (2012). Tropical montane cloud forests (Vol. 110). Springer Science \& Business Media, New York, 401 pp. https://dx.doi.org/10.1007/978-1-4612-2500-3.

Harris, N. L., Brown, S., Hagen, S. C. et al. (2012). Baseline map of carbon emissions from deforestation in tropical regions. Science, 336(6088), 1573-1576. https://dx.doi.org/10.1126/science.1217962. 
INEGI (2005). Instituto Nacional de Estadística, Geografía e Informática. Carta de Uso Actual de Suelo y Vegetación, Series III (2002), escala 1: 250 000. INEGI, México.

INEGI (2013). Uso Nacional de Tierras y Vegetación: Escala 1: 250000 (vector). Series V. DGG-INEGI, México.

Kim, D. H., J. O. Sexton, \& J. R. Townshend (2015). Accelerated deforestation in the humid tropics from the 1990s to the 2000s. Geophysical Research Letters ,42, 34953501. https://doi.org/10.1002/2014gl062777

Lambin, E. F., B. L. Turner, H. J. Geist, S. B. Agbola, A. Angelsen, J. W. Bruce, O. T. Coomes et al. (2001). The causes of land-use and land-cover change: moving beyond the myths. Global Environmental Change, 11, 261-269.

Leija, E. G., Reyes-Hernández, H., Fortanelli, J. et al. (2011). Current situation of the cloud forest in the state of San Luis Potosí. Research and Science, 53, 3-11.

Leija, E. G., H. Reyes-Hernández, O., Reyes-Pérez, J. L. Flores-Flores \& F. J. Sahagún-Sánchez (2016). Cambios en la cubierta vegetal, usos de la tierra y escenarios futuros en la región costera del estado de Oaxaca, México. Madera y Bosques 22(1), 125-140. https://doi.org/10.21829/myb.2016.221481

Leija, E. G., \& Pavón, N. P. (2017). The northernmost tropical rain forest of the Americas: Endangered by agriculture expansion. Tropical Ecology, 3, 641-652.

Leija, E. G, Pavón, N. P, Sánchez-González, A. et al. (2018). Cambio de cobertura terrestre y depósitos de carbono en un bosque nuboso montano tropical en la Sierra Madre Oriental, México. J. Mt. Sci., 15, 2136-2147. https://doi.org/10.1007/s11629-018-4937-y

Leija, E. G., Valenzuela-Ceballos, S. I., Valencia-Castro, M., Jiménez-González, G., CastañedaGaytán, G., Reyes-Hernández, H. \& Mendoza, M. E. (2020). Análisis de cambio en la cobertura vegetal y uso del suelo en la región centro-norte de México. El caso de la cuenca baja del río Nazas. Ecosistemas, 29(1), 1826. https://doi.org/https://10.7818/ECOS.1826

Mas, J. F. (2005). Change estimates by map comparison: A method to reduce erro-neous changes due to positional error. Transactions in GIS, 4, 619-629. https://doi.org/10.1111/j.1467-9671.2005.00238.x

Mas, J. F. \& Flamenco-Sandoval, A. (2011). Modelización de cambios en la cobertura/uso del suelo en una región tropical de México. GeoTropico, 1, 1-24. Recuperado de http://www.geotropico.org/NS_5_1_Mas-Flamenco.pdf

Mas, J. F., J. Reyes \& A. Pérez (2003). Evaluación de la confiabilidad temática de mapas o de imágenes clasificadas: una revisión. Boletín del Instituto de Geografía, UNAM, $51,53-72$.

Meneses-Tovar, C. L. (2011). El índice diferencial estandarizado de vegetación como indicador de degradación forestal. Unasylva, 238(62), 38-46. Recuperado de http://www.fao.org/3/i2560s/i2560s07.pdf

Munsi, M., S. Malaviya, G. Oinam, \& P. K. Joshi (2010). A landscape approach for quantifying land-use and land-cover change (1976-2006) in middle Himalaya. Regional Environmental Change, 10, 145-155.

Muñoz-Piña, C., G. Alarcón, J. C. Fernández \& L. Jaramillo (2003). Patrones de píxeles de deforestación en México. México: INE-Semarnat (Documento de trabajo). México, D.F., 26 pp. 
Navarrete, D., Méndez, D., Flamenco, A. et al. (2010). Situación actual, fragmentación, áreas de conservación prioritarias y principales amenazas del bosque mesófilo de montaña de Chiapas. En: Pérez Farrera, M.Á., Tejeda Cruz C., Silva Rivera, E. (Eds.) (2010). Los bosques mesófilos de montaña en Chiapas. Universidad de Ciencias y Artes de Chiapas, Tuxtla Gutiérrez, Chiapas, México, 295-326.

Newsham, A., Pulido, M. T., Ulrichs, M. et al. (2018). Ecosystems-based adaptation: Are we being conned? Evidence from Mexico. Global Environmental Change, 49, 14-26. https://doi.org/10.1016/j.gloenvcha.2018.01.001

Nolte, C., Warou, Y. L. P., Munger, J. et al. (2017). Conditions influencing the adoption of effective anti-deforestation policies in South America's commodity frontiers. Global Environmental Change, 43, 1-14.

https://doi.org/10.1016/j.gloenvcha.2017.01.001

Olofsson, P., Foody, G. M., Herold, M. et al. (2014). Good practices for estimating area and assessing accuracy of land change. Remote Sensing of Environment, 148, 42-57. https://doi.org/10.1016/j.rse.2014.02.015

Pérez-Verdín, G., Kim, Y. S., Hospodarsky et al. (2009). Factors driving deforestation in common pool resources in Northern Mexico. Journal of Environmental Management, 90, 331-340. https://doi.org/10.1016/j.jenvman.2007.10.001

Perry, G. L., \& Enright, N. J. (2006). Spatial modelling of vegetation change in dynamic landscapes: a review of methods and applications. Progress in Physical Geography, 30(1), 47-72.

Pijanowski, B. C., Brown, D. G., Shellito, B. A. et al. (2002). Using neural networks and GIS to forecast land use changes: A land transformation model. Computers, Environment and Urban Systems, 26, 553-576. https://doi.org/10.1016/S0198-9715(01)00015-1

Pompa, M. (2008). Análisis de la deforestación en ecosistemas montañosos del noroeste de México. Avances en Investigación Agropecuaria, 2, 35-43.

Ramírez-Bautista, A., Sánchez-González, A., Sánchez-Rojas. G. \& Cuevas-Cardona, C. (Eds.) (2017). Biodiversidad del estado de Hidalgo. Volumen II. Universidad Autónoma del Estado de Hidalgo-Consejo Nacional de Ciencia y Tecnología. Pachuca, Hidalgo, México, 368.

Ramírez, B. H., Teuling, A. J., \& Ganzeveld, L. et al. (2017). Tropical Montane Cloud Forests: Hydrometeorological variability in three neighbouring catchments with different forest cover. Journal of Hydrology, 552, 151-167. https://doi.org/10.1016/j.jhydrol.2017.06.023

Ramírez-García, A. G., Castillo-Escalante, I. C. (2009). El entorno socioeconómico de los municipios con presencia de bosque mesófilo en el estado de Hidalgo. En: Monterroso Rivas, A.I (Eds.) (2009). El bosque mesófilo de montaña en el estado de Hidalgo: perspectiva ecológica ante el cambio climático. $1^{\text {a }}$ ed. Universidad Autónoma Chapingo, México, 27-38.

Ray, D. K., Nair, U. S., Lawton, R. O. et al. (2006). Impact of land use on Costa Rican tropical montane cloud forests: Sensitivity of orographic cloud formation to deforestation in the plains. Journal of Geophysical Research 111(D02). https://doi.org/10.1029/2005JD006096

Reyes-Hernández, H., L. Olvera-Vargas, F. J. Sahagún-Sánchez, \& J. F. Mas. (2009). Transformation of the forest cover and future scenarios in the Sierra Madre Oriental, physiographic region, San Luis Potosí, México ISRSE 33. 33 
International Symposium on Remote Sensing of Environment. Sustaining the Millennium Development Goals. Recuperado de http://isrse-33.jrc.ec.europa.e.

Rodríguez-Laguna, R., Jiménez, P. J., Aguirre, C. O., Treviño-Garza, E. (2006). Estimación de carbono almacenado en un bosque de niebla en Tamaulipas, México. CIENCIA UANL, (9)2, 179-187.

Rosete-Vergés, F. A., J. L. Pérez-Damián, M. Villalobos-Delgado, E. N. Navarro-Salas, E. Salinas-Chávez \& R. Remond-Noa (2014). El avance de la deforestación en México 1976-2007. Madera y Bosques, 20, 21-35.

Ruíz, Y. M., Mendoza, M. E., Huicochea, G. E. S. et al. (2016). Dinámica espacio-temporal del bosque de niebla y su estado sucesional en el estado de Michoacán, México. Geografía y sistemas de información geográfica (GEOSIG), 8, 233-247.

Sahagún, J., H. Reyes-Hernández, J. L. Flores, \& L. Chapa. (2011). Modeling scenarios of the potential change in the vegetation and land use in the Sierra Madre Oriental of San Luis Potosi, Mexico. Journal of Latin American Geography, 2(11), 65-86.

Sandel, B., \& Svenning, J. C. (2013). Human impacts drive a global topographic signature in tree cover. Nature Communications, 4, 2474. https://doi.org/10.1038/ncomms3474

Simonet, G., Subervie, J., Ezzine-de-Blas, D. et al. (2018). Effectiveness of a REDD+ Project in Reducing Deforestation in the Brazilian Amazon. American Journal of Agricultural Economics, 101(1), 1-19. https://doi.org/10.1093/ajae/aay028

Soares-Filho, B. S., Alencar, A. A., Nepstad, D. C. et al. (2004). Simulating the response of land-cover changes to road paving and governance along a major Amazon highway: The Santarém Cuiabá corridor. Global Change Biology, 5, 745-764. https://doi.org/10.1111/j.1529-8817.2003.00769.x

Soares-Filho, B. S., Nepstad, D. C., Curran, L. M. et al. (2006). Modelling conservation in the Amazon basin. Nature 440: 520-523. https://doi.org/10.1038/nature04389

Soares-Filho, B. S., Pennachin, C. L., \& Cerqueira, G. (2002). Dinamica a stochastic cellular automata model designed to simulate the landscape dynamics in an Amazonian colonization frontier. Ecological Modelling, 154, 217-235. https://doi.org/10.1016/S0304-3800(02)00059-5

Spracklen, D. V., \& Righelato, R. (2014). Tropical montane forests are a larger than expected global carbon store. Biogeosciences, 10, 2741-2754. https://doi.org/10.5194/bg-11-2741-2014

Stehman, S. \& R. Czaplewski (1998) Design and analysis for thematic map accuracy assessment: fundamental principles. Remote Sensing of Environment 64, 331344. Recuperado de https://www.fs.fed.us/rm/pubs_other/rmrs_1998_stehman_s001.pdf

Toledo, V. M. (1990). El proceso de ganaderización y la destrucción biológica y ecológica en México. In E. Leff (Ed.) Medio ambiente y desarrollo en México. Centro de Investigaciones Interdisciplinarias en Humanidades, 191-227. Universidad Nacional Autónoma de México, México.

Turner, K. G., Anderson, S., Gonzales-Chang, M. et al. (2016). A review of methods, data, and models to assess changes in the value of ecosystem services from land degradation and restoration. Ecological Modelling, 319, 190-207.

Watson, R. T., Noble, I. R., Bolin, B. et al. (Eds.) (2001). Land use, land use change, and forestry. Cambridge University Press. Cambridge, 375. Recuperado de http://asiannature.org/sites/default/files/2000\%20Watson\%20IPCC.pdf 
Weatherley-Singh, \& J., Gupta, A. (2015). Drivers of deforestation and REDD+ benefit sharing: A meta-analysis of the (missing) link. Environmental Science \& Policy, 54, 97-105. https://doi.org/10.1016/j.envsci.2015.06.017

Wright, J. S. (2005). Tropical forests in a changing environment. Ecology and Evolution, 20, 553-560. https://doi.org/10.1016/j.tree.2005.07.009

Xu C., Li Y., Hu J. et al. (2012). Evaluating the difference between the normalized difference vegetation index and net primary productivity as the indicators of vegetation vigor assessment at landscape scale. Environmental Monitoring and Assessment, 184, 1275-1286. https://doi.org/10.1007/s10661-011-2039-1

Yu G., Chen Z., Shilong P. et al. (2014). High carbon dioxide uptake by subtropical forest ecosystems in the East Asia monsoon region. Proceedings National Academy Sciences. USA, 111, 4910-4915. https://doi.org/10.1073/pnas.1317065111 